\title{
Auditory Brainstem Response Abnormalities in Autistic Children
}

\author{
M.J. TAYLOR, B. ROSENBLATT, and L. LINSCHOTEN
}

SUMMARY: In an attempt to clarify issues of brainstem dysfunction and hearing thresholds in autistic. children, we studied the A uditory Brainstem Responses (ABRs) in 32 children who clearly fit within the criteria of autism established by the National Society for Autistic Children (1977). $A B R s$ were recorded between $C z$ and ipsilateral ear in response to click stimuli. Interwave latencies and auditory threshold in each ear were determined. Of the 32 children, 11 had moderate hearing loss ( 8 bilaterally) and 3 had severe to profound hearing loss, all bilaterally. 8 of the 14 with hearing loss also had as-

RÉSUMÉ:Afin de clarifier certains aspects des dysfonctions du tronc cérébral et des seuils d'audition chez les enfants autistiques, nous avons étudié les $A B R$ chez 32 enfants répondant à tous les critères de la National Society for Autistic Children (1977). Les $A B R$ furent enregistrés entre le $\mathrm{Cz}$ et l'oreille ipsilatérale en réponse à un stimulus "click". Nous avons mesuré la latence interonde et le seuil auditif dans chaque oreille. Des 32 enfants, 11 avaient une perte auditive modérée ( 8 bilatéralement), 3 une perte sévère (tous bilatéralement). Des 14 enfants avec atteinte auditive, 8 avaient aussi des symptômes as- sociated features (e.g., perinatal encephalopathy). The I-III and I-V interwave latencies were significantly longer in the autistic children compared to normal control children; the increased conduction times were found mainly in the early portion of the auditory brainstem pathway. These data confirm some earlier reports of $A B R$ abnormalities in autistic children and are concordant with some theories of the etiological basis of autism. The high incidence of hearing loss in these children is significant and routine $A B R$ testing is recommended.

sociés comme une encéphalopathie périnatale. Chez les enfants autistiques, par rapport aux témoins, les latences interondes $I-I I I$ et $I-V$ étaient signativement plus longues et la variabilité des résultats plus grande. Les temps de conduction allongés touchaient surtout le tronc cérébral. Ces données confirment des rapports antérieurs indiquant la présence d'anomalies $A B R$ chez les enfants autistiques et sont compatibles avec certaines théories étiologiques de l'autisme. Nous recommendons la mesure systématique des $A B R$ ches ces enfants.
Childhood autism is a behaviourally defined syndrome whose symptoms include early onset developmental disturbances in language, in cognition, in the modulation of sensory input and in the ability to relate to others. Although Kanner (1943) first described autism as a psychogenic disorder, this has been supplanted by a variety of theories of organic disturbance of the central nervous system. Some autistic children have associated CNS dysfunction or have suffered known insults (e.g., epilepsy, asphyxia) but the majority have no demonstrable neuropathology or cause. Yet the consensus of many investigators is that the syndrome is expressive of an underlying neuropathological process (Ornitz \& Ritvo, 1976).

Several reports have proposed brainstem or midbrain dysfunction to be the underlying common pathology (McCulloch \& Williams, 1971; Ornitz et al., 1974). Abnormalities in vestibular nystagmus, visual vestibular interactions and eye movements during REM suggested to several researchers the existence of brainstem dysfunction (Pollack \& Krieger, 1958; Colbert et al., 1959; Ritvo et al., 1969; Ornitz et al., 1974, 1969), and Ornitz \& Ritvo (1976) have argued that brainstem pathology could account for many of the constellation of symptoms that define autism. Simon (1975) suggested that damage to the brainstem auditory system could produce the stereotypic, abnormal language so characteristic in autistic children. Brief periods of asphyxia were proposed to account for the brainstem damage, as similar behavioural effects to autism have been found in monkeys submitted to asphyxia at birth (Meyers, 1972).

In an attempt to pursue the issue of brainstem dysfunction, several researchers have studied auditory brainstem responses (ABRs) in autistic children. The ABR is a widely accepted
From the Montreal. Children's Hospital, Montreal, Canada.

Requests for reprints: Dr. M. J. Taylor, Division of Neurology, Hospital for Sick Children, 555 University Avenue, Toronto, Ontario, M5G 1 X8. 
clinical measure of the integrity of the auditory brainstem pathway from the VIIIth nerve to the inferior colliculus (Starr \& Achor, 1975; Stockard et al., 1977; Stockard \& Rossiter, 1977); the latency of the ABR waves varies with auditory threshold, and the interwave latencies and morphology vary with brainstem abnormalities. Student \& Sohmer (1978) initiated investigation in this field with a report of abnormally long interwave latencies in the ABRs in autistic children, although they later withdrew this conclusion (Student \& Sohmer, 1979). More recent reports, however, have found abnormalities in the auditory system. Novick et al. (1980) recorded ABRs and cortical auditory evoked responses in 5 autistic adolescents. Abnormally long ABR latencies were found in 1 autistic patient and smaller amplitude cortical potentials were seen in all 5 compared to normal controls. Skoff et al. (1980) tested a larger, although less well defined group of autistic children; the children were institutionalized with a prior diagnosis of autism. Increased I$\mathrm{V}$ and III-V interwave latencies were found in 9 of the 16 autistic children from whom data could be obtained.

Rosenblum et al. (1980) reported increased latencies and variability in 6 autistic children. They found increased interwave latencies and increased latencies of their waves III and IV in the autistic children. They also found the within-subject, between-trial variability was greater in the autistic group, primarily in the early portion of the waveform. They suggested that this indicated a defect in the synaptic efficiency within the first two synapses of the auditory pathway. They did not comment on whether the amount of movement artefact in the records of the two groups was the same; movement or tension on the part of the patient will increase the variability of the responses.

Although Student \& Sohmer (1978) found no ABRs in 5 of their 15 autistic patients, and concluded profound peripheral hearing loss, subsequent studies have reported no hearing impairments. Skoff et al. (1980) found no responses unilaterally in 11 of their patients, yet did not seem to consider the possibility of hearing loss. The ABR has been shown to be a reliable and accurate means of determining auditory threshold in infants and children who are difficult to test (Picton \& Smith, 1978; Despland \& Galambos, 1980; Mokotoff et al., 1977), and threshold abnormalities may have influenced the results of Skoff et al.

Problems arising with the above studies include poor definition of autism, poor cooperation of the patients and small numbers of patients. The present study attempted to avoid these difficulties, in order to gain a clearer understanding of both the possible dysfunction in the auditory brainstem pathway and in the hearing thresholds in autistic children.

\section{Subjects}

\section{Methods}

32 autistic children ( 11 female), as defined by the criteria of the National Society for Autistic Children (Ritvo, 1977) were tested in this study. The criteria can be summarized under the following five categories: 1 ) onset prior to 30 months, disturbances of 2) developmental rate, 3) responsiveness to sensory stimuli, 4) language and cognition and 5) relating to people, events and objects. The children were all given a complete neurological examination by a pediatric neurologist who determined whether each child fit within the defined limits of autism. Any associated disorders were noted at this time. The examination was done independently of the ABR testing and the two sets of results were not compiled until the entire group had been tested. Children who were previously diagnosed as autistic but did not fit within the above criteria were not included. The ages ranged from 2.5 to 15 years with a mean of 8.4 years. 22 audiologically and neurologically normal children (10 female) ranging in age from 3 to 16 years, with a mean of 10.3 years, served as controls.

\section{Procedure}

Approximately half an hour prior to testing the autistic children received intramuscularly a sedation consisting of meperidine, droperidol and hydroxyzine with a dosage of 1.0, 0.1 and 1.0 $\mathrm{mg} / \mathrm{kg}$, respectively, with a maximum to $30 \mathrm{~kg}$. Without sedation the autistic children were uncooperative and produced too much EMG artefact in the EEG for reliable recordings to be obtained. None of the normal controls received any sedation; they cooperated for the testing and many fell asleep.

ABRs were recorded from all patients using a Grass Model 10 Evoked Response System, with high and low pass filter settings of 100 and $3 \mathrm{k} \mathrm{Hz}$, respectively, and a gain of $100 \mathrm{k}$. The ABRs were recorded between $\mathrm{Cz}$ and ipsilateral earlobe using Grass gold cup electrodes attached with paste and gauze. Electrode impedance was below 5 kOhms. Two averages of 1024 trials were obtained at each intensity level tested to assure replicability of the responses.

Rarefaction $100 \mu \mathrm{sec}$ unfiltered clicks were presented monaurally via Telex 1470 headphones; a continuous white noise mask was presented contralaterally to avoid cross-stimulation. Clicks were presented at $11 / \mathrm{sec}$ at 70 dBHL ( $70 \mathrm{~dB}$ above the average hearing threshold of 10 normal hearing adults in the lab). When clear replicable responses were obtained, clicks were then presented at a rate of $51 / \mathrm{sec}$ and the intensity reduced until no response was obtained (i.e., threshold was reached). Where a clear response was not found at $70 \mathrm{dBHL}$ the intensity was increased in $10 \mathrm{~dB}$ steps until a complete waveform was recorded, and then threshold was determined. No intensity level higher than $100 \mathrm{~dB}$ was employed.

\section{RESULTS}

The hearing thresholds, as determined by the ABRs, were found to be abnormally high in many of the autistic children. Of the 32 tested, 11 had moderate hearing loss (threshold of 40$60 \mathrm{dBHL}$ ), 3 had unilateral and 8 bilateral hearing loss. 3 other autistic children had bilateral severe to profound hearing loss (thresholds of 70 $\mathrm{dBHL}$ or greater). The raised thresholds were not a function of poorer resolution of the waveforms at the lower intensity levels in the autistic children; figure 1 shows threshold 


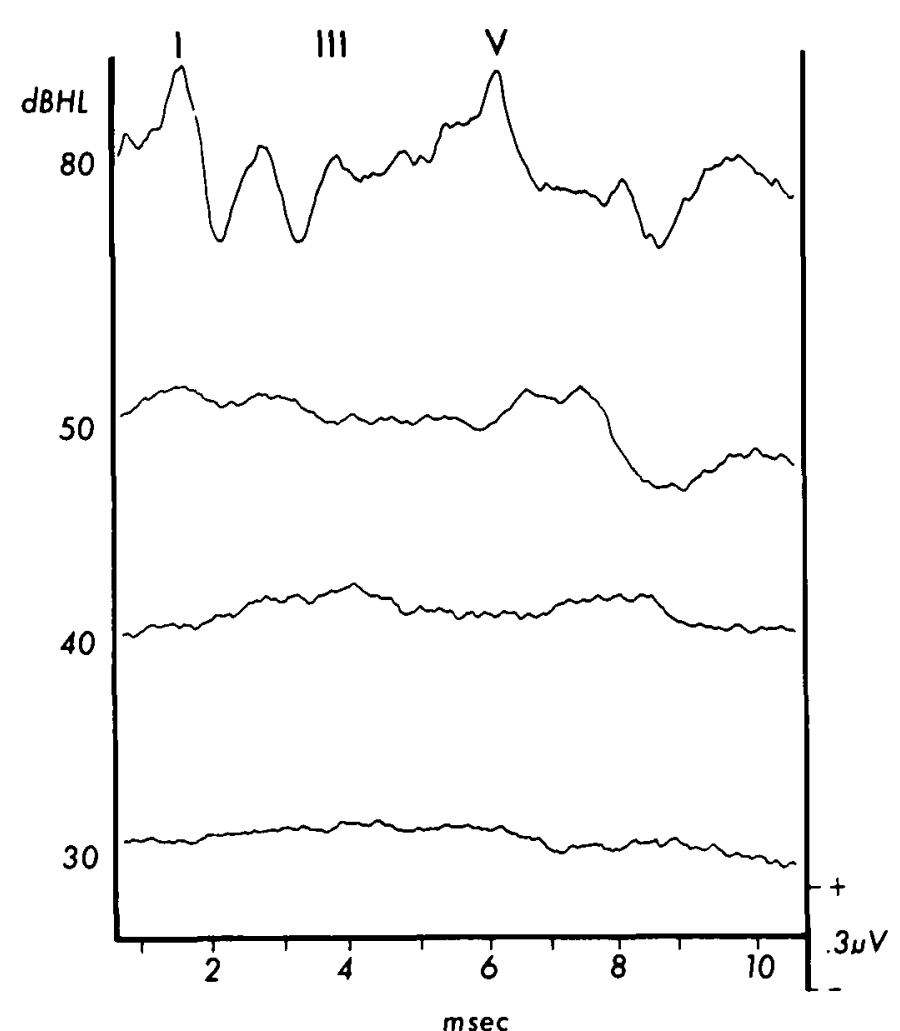

Figure 1 - Auditory threshold determination in an autistic child. Wave $\mathrm{V}$ is clearly seen at 50 and $40 \mathrm{dBHL}$, but absent at $30 \mathrm{dBHL}$, indicating a raised threshold at $40 \mathrm{dBHL}$.

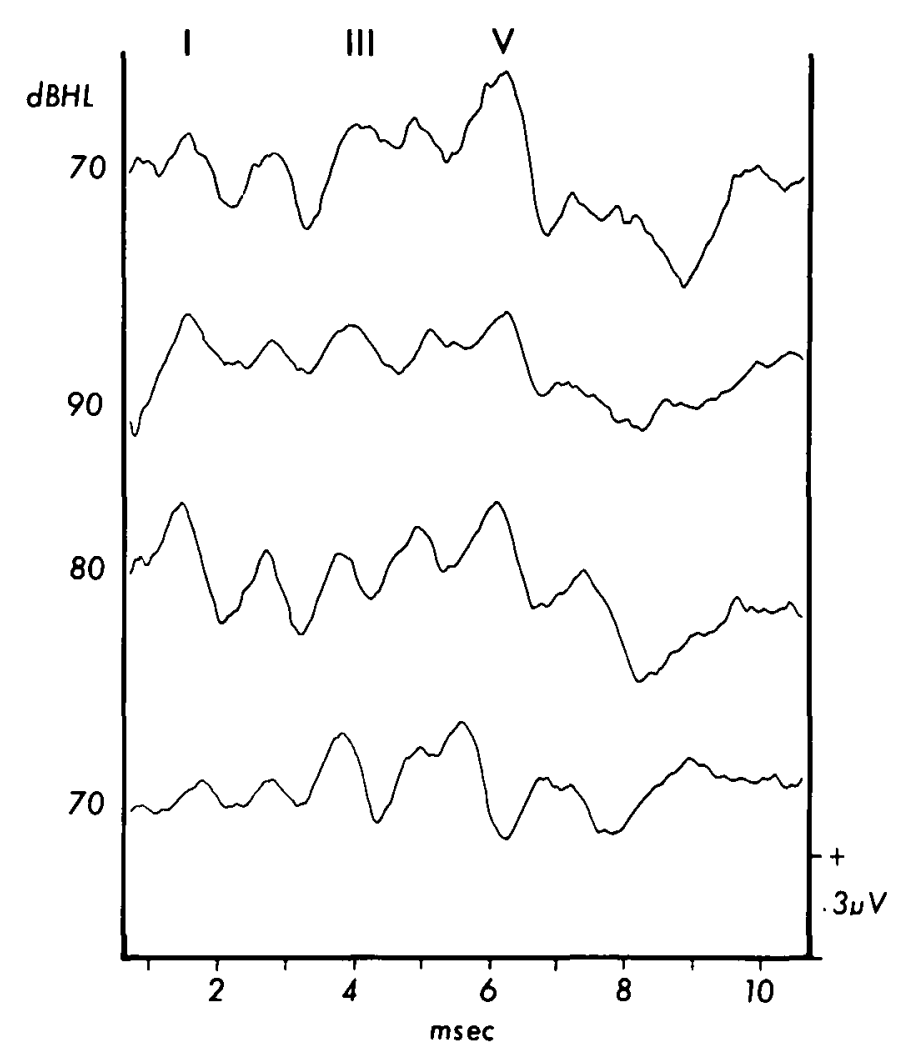

Figure 2 - ABRs from three autistic children (three top traces) showing the increased $I-V$ interwave latencies compared to a normal control child's response (bottom trace). determination in one autistic child. The thresholds in the normal control children, as determined by the ABR were usually $10 \mathrm{dBHL}$, although in some cases were $20 \mathrm{dBHL}$. Only threshold levels of $40 \mathrm{dBHL}$ and above were considered abnormal.

The autistic children were divided into two subgroups, those with and those without known associated neurological disorders (such as microcrania, perinatal encephalopathy, tuberous sclerosis); there were 13 and 19 in each group, respectively. Of the 13 children with associated disorders (group A), 8 had some hearing loss, 5 moderate ( 3 bilateral) and 3 severe to profound. Of the 19 children without associated disorders (group B) 6 suffered moderate hearing loss ( 5 bilateral).

An analysis of variance was performed on the interwave latencies for the two groups of autistic children and no significant differences were found on any of the measures. The data was therefore collapsed across these two groups for further analysis. The ab- solute wave latencies were not analyzed as they were not comparable due to the high percentage of children with hearing loss in the autistic group.

The I-III, I-V and III-V interwave latencies of the autistic and control children were submitted to a repeated measures analysis of variance. Significant differences were found in the I-III and $\mathrm{I}-\mathrm{V}$ interwave latencies $(\mathrm{F}(1,50)=$ $15.94, \mathrm{p}<.001 ; \mathrm{F}(1,50)=15.68$, $\mathrm{p}<.001$, respectively), the autistic children having significantly longer interwave latencies than the normals. There were no differences between the groups on the III-V latency, between the ear tested, nor any interactions of these factors. Table 1 contains the mean interwave latencies for the autistic and normal children. The variability of the data from the autistic children was also greater than that from the normal controls on all of the interwave measures (Table 1).

13 autistic children, 5 from group $A$ and 8 from group $B$ had increased interwave latencies beyond the normal

\begin{tabular}{|c|c|c|c|c|}
\hline \multicolumn{5}{|c|}{$\begin{array}{c}\text { TABLE 1 } \\
\text { AUDITORY BRAINSTEM RESPONSE } \\
\text { INTERWAVE LATENCIES }\end{array}$} \\
\hline & $\begin{array}{l}\text { Autistic } \\
\text { children }\end{array}$ & $\begin{array}{l}\text { Normal } \\
\text { children }\end{array}$ & & \\
\hline & $\bar{X} \quad$ s.d. & $\overline{\mathrm{X}} \quad$ s.d. & $\mathrm{F}$ & $\mathrm{p}<$ \\
\hline I-III & $2.23 \quad .23$ & 2.04 .13 & 15.94 & .0002 \\
\hline III-V & $1.96 \quad 20$ & 1.86 .16 & 2.79 & n.s \\
\hline I-V & $4.18 \quad .34$ & 3.90 .18 & 15.68 & .0002 \\
\hline
\end{tabular}

limits of the control group (2.5 standard deviations above the mean, $\mathrm{p}<.01$ ). These children were not distinguishable as a group from the remaining autistic children on any of the clinical or behavioural symptoms such as language development.

\section{DISCUSSION}

The data presented here demonstrate $44 \%$ of the autistic group of children had some significant hearing loss in at least one ear. This type of information was previously unavailable due to the difficulty involved in testing autistic children using traditional audiometric methods. In addition I-III and I-V in- 
terwave latencies, which measure brainstem conduction time, were significantly longer in the autistic children compared to normal controls.

The results of the $A B R$ regarding hearing function argue very strongly for this testing to be conducted routinely with all autistic children. Standard audiometric testing in these children is often impossible and when obtained is often imprecise in determining the hearing levels in both ears. Hearing loss though clearly not the cause of autism, could further impede development in autistic children, particularly language development. The risk factors for hearing loss appear to be much higher in the autistic children with other associated neurological disorders; this may reflect diffuse pathology in the nervous system of these children. Increased risk factors for children with a history of perinatal insult requiring hospitalization has been shown in several reports of increased risk of hearing loss in infants in intensive care nurseries (e.g., Despland \& Galambos, 1980) although the frequency of $A B R$ abnormalities in these autistic children is still much higher than that found in the high-risk neonates. The hearing losses in autism, like the autistic syndrome itself, cannot be explained simply by the sundry associated features found in these children.

Although a procedural difference between the two groups of children was the use of sedation only in the autistic children, this is unlikely to have produced the ABR abnormalities. Many studies have shown that the ABR is not affected by arousal level, sleep, sedation, general anesthesia or a variety of centrally acting drugs (Sohmer et al., 1978; Sanders et al., 1979; Duncan et al., 1979; Uziel \& Benezechy, 1978; Stockard et al., 1977; Starr \& Achor, 1975). In these studies neither the ABR interwave latencies nor auditory threshold determination changed as a function of the administered drug or state of arousal. Thus, although it remains a possibility that our sedation influenced our results, we feel this is improbable.

The increased interwave latencies in the ABR data from the autistic children confirm some earlier reports in the literature. Skoff et al. (1980) found increased III-V interwave latencies, while Rosenblum et al. (1980) found the I-III interval to be often abnormal. Increased $\mathrm{I}-\mathrm{V}$ interwave latencies in the present study were due primarily to increased I-III latencies; the III-V interwave latency was beyond the normal limits in only 5 of the 61 ABRs in which latencies could be determined. Our finding of greater variability in the ABRs from the autistic children was not due to increased artefact in the recordings of the autistic children as all were sedated during the testing.

The increased I-V latencies suggest that neurophysiological dysfunction can occur in the brainstem in many autistic children, in general accord with several proposed models of autism. Simon (1975) suggested auditory brainstem dysfunction to be the cause of speech disturbances in autism, postulating that the inferior colliculus was the most likely site of damage. Our data would not fit closely with her model since the increased latencies were in the earliest portion of the ABR and there appeared to be no relationship between extent of language in these children and the ABR abnormalities. However, damage anywhere in the auditory system could certainly contribute to poor language development, and we did find evidence of brainstem auditory pathway dysfunction.

Our results may also have some implications for the theory of vestibular nuclei abnormalities in autistic children (Ritvo et al., 1969; Ornitz et al., 1969; 1974). These researchers have suggested that the perceptual inconstancy symptomatic of autism is due to a unitary organic dysfunction in the vestibular nuclei. Although the cochlear and vestibular fibres in the VIIIth nerve diverge soon after entering the brainstem, their nuclei are adjacent. One might speculate that ABR abnormalities that reflect dysfunction in the early portion of the auditory brainstem pathway might also reflect pathology involving the vestibular nuclei, due to the proximity of the structures.

Several researchers have proposed a model of the etiology of autism that involves more rostral areas of the brain including the ring of mesolimbic cortex, the neostriatum and the thalamus (Damasio \& Maurer, 1978; Delong et al., 1981; Coleman, 1979); these structures form the target area of dopaminergic neurons. Although our data do not bear directly on this model, the fact that the cells of the dopaminergic system arise in the brainstem allows one to speculate that brainstem pathology could also affect these more rostral structures.

We feel this study is significant in demonstrating two types of abnormalities in the auditory system. We found increased hearing thresholds and increased conduction times through the brainstem in a large percentage of a carefully diagnosed group of autistic children.

\section{REFERENCES}

COLEMAN, M. (1979). Studies of the autistic syndrome. In Congenital and Acquired Cognitive Disorders, R. Katzman (Ed.), Raven Press: New York.

COLBERT, E.G., KOEGLER, R.R. \& MARKHAM, C.H. (1959). Vestibular dysfunction in childhood schizophrenia. Archives of General Psychiatry, 1:600-617.

DAMASIO, A.R. \& MAURER, R.G. (1978). A neurological model for childhood autism. Archives of Neurology, 35:777-786.

DELONG, G.R., BEAN, C. \& BROWN, F.R. (1981). Acquired reversible autistic syndrome in acute encephalopathic illness in children. Archives of Neurology, 38:191194.

DESPLAND, P. \& GALAMBOS, R. (1980). The auditory brainstem response (ABR) is a useful diagnostic tool in the intensive care nursery. Pediatric Research, 14:154-158.

DUNCAN, P.G., SANDERS, R.A. \& McCULLOCH, D.W. (1979). Preservation of auditory-evoked brainstem responses in anaesthetized children. Canadian Anaesthesiology Society Journal, 26:492-495.

KANNER, L. (1943). Autistic disturbances of affective contact. Nervous Child, 2:217-250.

MacCULLOCH, M.J. \& WILliaMS, C. (1971). On the nature of infantile autism. Acta Psychiatry Scandanavian, 47:295-314.

MEYERS, R.E. (1972). Two patterns of perinatal brain damage and the conditions of occurrence. American Journal of Obstetrics and Gynecology, 112:246-276.

MOKOTOFF, B., SCHULMAN-GALAMBOS, C. \& GALAMBOS, R. (1977). Brainstem auditory evoked responses in children. Archives Otolaryngology, 103:38-43. 
NOVICK, B., VAUGHAN, H.G., KURTZBURG, D. \& SIMSON, R. (1980). An electrophysiologic indication of auditory processing defects in autism. Psychiatric Research, 3:107-114.

ORNITZ, E.M., BROWN, M.B., MASON, A. et al. (1974). Effect of visual input on vestibular nystagmus in autistic children. Archives of General Psychiatry, 31:369375 .

ORNITZ, E.M. FORSYTHE, A.B., TANGUAY, P.E., et al. (1974). The recovery cycle of the averaged auditory evoked response during sleep in autistic children. Electroencephalography and clinical Neurophysiology, 37:173-174.

ORNITZ, E.M. \& RITVO, E.R. (1976). The syndrome of autism: A critical review. The American Journal of Psychiatry, 133: 609621 .

ORNITZ, E.M., RITVO, E.R., BROWN, M.B., et al. (1969). The EEG and rapid eye movements during REM sleep in normal and autistic children. Electroencephalography and clinical Neurophysiology, 26:167-175.

PICTON, T.W. \& SMITH, A.D. (1978). The practice of evoked potential audiometry. Otolaryngology Clinics of North America, $11: 263-282$

POLLACK, M. \& KRIEGER, H.P. (1958). Oculomotor and postural patterns in schizophrenic children. Archives of Neurology and Psychiatry, 79:720-726.
RITVO, E.R. (1977). National Society for Autistic Children: Definition of the Syndrome of Autism. July.

RITVO, E.R., ORNITZ, E.M., EVIATAR, A., et al. (1969). Decreased postrotatory nystagmus in early infantile autism. Neurology, 19:653-658.

ROSENBLUM, S.M., ARICK, J.R., KRUG, D.A., et al. (1980). Auditory brainstem evoked responses in autistic children. Journal of Autism and Developmental Disorders, 10:215-225.

SANDERS, R.A., DUNCAN, P.G. \& McCUllough, D. W. (1979). Clinical experience with brainstem audiometry performed under general anesthesia. Journal of Otolaryngology, 8:24-32.

SKOFF, B.F., MIRSK Y, A.F. \& TURNER, D. (1980). Prolonged brainstem transmission time in autism. Psychiatry Research, 2:157166.

SIMON, N. (1975). Echolalic speech in childhood autism. Archives of General Psychiatry, 32:1439-1446.

SOHMER, H., GAFNI, M. \& CHISIN, R. (1978). Auditory nerve and brainstem responses: Comparison in awake and un conscious subjects. Archives of Neurology, $35: 228-230$.

STARR, A. \& ACHOR, L.J. (1975). Auditory brainstem responses in neurological disease. Archives of Neurology, 36:761-772.
STARR, A. \& HAMILTON, A.E. (1976). Correlation between confirmed sites of neurological lesions and abnormalities of far-field auditory brainstem responses. Electroencephalography and clinical Neurophysiology, $41: 595-608$.

STOCKARD, J.J. \& ROSSITER, V.S. (1977). Clinical and pathologic correlates of brainstem auditory response abnormalities. Neurology, 27:316-325.

STOCKARD, J.J., ROSSITER, V.S., JONES, T.A. \& SHARBROUGH, F.W. (1977). Eifects of centrally acting drugs on brainstem auditory responses. Electroencephalography and clinical Neurophysiology, 43:550-551.

STOCKARD, J.J., STOCKARD, J.E. \& SHARBROUGH, F.W. (1977). Detection and localization of occult lesions with brainstem auditory response. Mayo Clinic Proceedings, 52:761-769.

STUDENT, M. \& SOHMER, H. (1978). Evidence from auditory nerve and brainstem evoked responses for an organic brain lesion in children with autistic traits. Journal of Autism and Childhood Schizophrenia, 8:1320.

STUDENT, M. \& SOHMER, H. (1979). Erratum. Journal of Autism and Developmental Disorders, 9:309.

UZIEL, A. \& BENEZECH, J. (1978). Auditory brainstem responses in comatose patients: Relationship with brainstem reflexes and levels of coma. Electroencephalography and Clinical Neurophysiology, 45:515-524. 